\title{
Long-Term Changes in Video Head Impulse and Caloric Tests in Patients with Unilateral Vestibular Neuritis
}

\author{
Hyun-Jin Lee ${ }^{1}$, Sung Huhn Kim², and Jinsei Jung ${ }^{2}$ \\ ${ }^{I}$ Department of Otorhinolaryngology, Gyeongsang National University Changwon Hospital, Changwon; and \\ ${ }^{2}$ Department of Otorhinolaryngology, Yonsei University College of Medicine, Seoul, Korea \\ 전정신경염 환자에서 비디오두부충동검사 및 칼로릭검사의 장기추적결과의 분석 \\ 이현진 ${ }^{1} \cdot$ 김성헌 $^{2} \cdot$ 정진세 ${ }^{2}$ \\ 경상대학교 창원병원 이비인후과학교실, ${ }^{1}$ 연세대학교 의과대학 이비인후과학교실 ${ }^{2}$
}

\author{
Received December 20, 2017 \\ Revised February 5, 2018 \\ Accepted February 14, 2018 \\ Address for correspondence \\ Jinsei Jung, MD, PhD \\ Department of Otorhinolaryngology, \\ Yonsei University \\ College of Medicine, 50 Yonsei-ro, \\ Seodaemun-gu, Seoul 03722, Korea \\ Tel $+82-2-2228-3619$ \\ Fax $+82-2-393-3617$ \\ E-mail jsjung@yuhs.ac
}

Background and Objectives Video head impulse tests (vHITs) and caloric tests are widely used to assess the loss of vestibular function in acute vestibular neuritis. Although previous studies have reported on the results of each test, longitudinal comparison of these tests is rare. In the present study, vHITs and caloric tests were performed in patients with unilateral vestibular neuritis during the acute phase and after a long follow-up period ( $>6$ months). The goal of this study was to evaluate the changes in vHIT and caloric test results and to analyze the relationships between them.

Subjects and Method Between September 2013 and December 2015, charts from 13 patients with unilateral vestibular neuritis were retrospectively reviewed. Among the 13 patients, caloric tests and vHITs were performed in 9 and 10 patients, respectively. Results of the vHITs and caloric tests were analyzed and the changes were compared.

Results During the acute phase of vestibular neuritis, the results of the caloric test showed an increase in canal paresis (CP), and the results of the vHIT showed a decrease in horizontal gain. Although subjective symptoms improved in all patients after a long follow-up period (mean: 13.9 months), the occurrence of CP determined from the caloric test was not significantly changed $(p=0.889)$. On the other hand, the mean horizontal gain of the vHIT had improved significantly $(p<0.05)$.

Conclusion While CP determined from the caloric test did not change after a long follow-up period, the decreased horizontal gain in the vHIT was significantly recovered in patients with unilateral vestibular neuritis. Korean J Otorhinolaryngol-Head Neck Surg 2019;62(1):23-7

Key Words Caloric test · Vestibular neuritis · Video head impulse test.

\section{Introduction}

Vestibular neuritis (VN) is defined as a sudden unilateral loss of vestibular function. ${ }^{1)}$ It is the most common cause of acute spontaneous vertigo and the third most common cause of peripheral vestibular disease. ${ }^{2-4)}$ Since $\mathrm{VN}$ is mostly caused

This is an Open Access article distributed under the terms of the Creative Commons Attribution Non-Commercial License (https://creativecommons.org/licenses/by-nc/4.0) which permits unrestricted non-commercial use, distribution, and reproduction in any medium, provided the original work is properly cited. by involvement of the superior vestibular nerve, caloric test, which evaluates the unilateral vestibular deficit by studying the vestibulo-ocular reflex (VOR) of the horizontal semicircular canal, has been widely used as a gold standard for VN diagnosis. This examination allows quantitative evaluation of vestibular function by comparison of the results to those of the contralateral side. However, caloric test stimulates non-physiologic low VOR frequencies $(0.002-0.004 \mathrm{~Hz})$, and normal results can be obtained in some cases of $\mathrm{VN}$ involv- 
ing the inferior vestibular nerve.

Recently, a new quantitative test of vestibular function, known as the video head impulse test (vHIT), has been developed. vHIT is known to have better sensitivity and specificity than the bedside head impulse test. ${ }^{5)}$ It also stimulates more physiologic high frequencies $(2-5 \mathrm{~Hz})$ compared to the caloric test. $\left.{ }^{6}\right)$ The sensitivity of the vHIT largely correlates with that of the caloric test in the acute phase of peripheral vestibulopathy. However, several studies have reported dissociation in the results between these two tests in the nonacute phase of $\mathrm{VN}^{7-9)}$ Most of these reports were based on comparisons of results at the time of the test. To compare these two tests more thoroughly, investigating the results longitudinally is necessary. Although a few studies have reported results of longitudinal comparison, their follow-up period was relatively short (within 3 months). ${ }^{7,8)}$ Considering that the remaining canal paresis $(\mathrm{CP})$ obtained from the caloric test is approximately $30 \%$ after one year of onset of the condition, ${ }^{10)}$ it is more reasonable to evaluate the results with a longer follow-up period. Therefore, the objective of this study was to compare caloric test and vHIT results after more than 6 months of follow-up and analyze changes in their results in patients with unilateral VN.

\section{Subjects and Method}

\section{Patients}

Between September 2013 and December 2015, 48 patients were initially diagnosed with $\mathrm{VN}$ through caloric test. Of these 48 patients, charts from the thirteen patients who un- derwent an additional caloric test or vHIT at follow-up were retrospectively reviewed (Table 1). The included patients consisted of eight men and five women who ranged in age from 29 to 82 (mean: $54.3 \pm 14.3$ ) years. Caloric tests were conducted in nine patients, and vHITs were conducted in ten patients. To thoroughly compare the changes in the results of the two tests, data from the six patients who underwent both tests were analyzed separately. All enrolled patients underwent vHITs or caloric tests within one month after experiencing symptoms of dizziness. In cases where patients received both tests during follow-up, the vHIT and caloric tests were performed on the same day. The mean follow-up duration was $13.8 \pm 11.9$ months (range: $6-50$ months). The Local Ethical Committee of Yonsei University approved this study (approval number: 4-2015-0534).

\section{Caloric tests and vHITs}

Detailed processes of the caloric tests and vHITs were described in our previous study. ${ }^{11)}$ A conventional bi-thermal caloric test was performed with a binocular video oculography system (SLMed, Seoul, Korea) with the patient in a supine position with $30^{\circ}$ of head flexion. Each ear canal was stimulated for 30 seconds separately with water at temperatures of $30^{\circ} \mathrm{C}$ and $44^{\circ} \mathrm{C}$, with a pause of 5 minutes between the two. CP in the caloric response was quantified according to Jongkee's formula. ${ }^{12)}$ A CP value $\geq 25 \%$ was regarded as pathological according to our normative data.

We used a vHIT device (ICS Impulse, GN Otometrics, Taastrup, Denmark) to evaluate horizontal semicircular canal functions. Patients were seated upright with $30^{\circ}$ of head flex-

Table 1. Detailed characteristics of patients

\begin{tabular}{cllllcccccc}
\hline $\begin{array}{c}\text { Patient } \\
\text { No. }\end{array}$ & Sex & Age & Site & Disease & $\begin{array}{c}\text { Initial CP } \\
(\%)\end{array}$ & $\begin{array}{c}\text { Initial gain } \\
\text { of vHIT }\end{array}$ & F/U test & $\begin{array}{c}\text { F/U CP } \\
(\%)\end{array}$ & $\begin{array}{c}\text { F/U gain } \\
\text { of vHIT }\end{array}$ & $\begin{array}{c}\text { F/U period } \\
(\mathrm{months})\end{array}$ \\
\hline 1 & Male & 71 & Right & AVN & 83.29 & 0.16 & Caloric test/ vHIT & 91 & 0.45 & 27.2 \\
2 & Female & 43 & Left & AVN & 74.82 & 0.28 & Caloric test/ vHIT & 76.7 & 0.56 & 9.0 \\
3 & Male & 82 & Right & AVN & 84.75 & 0.77 & Caloric test/ vHIT & 70 & 1.12 & 13.8 \\
4 & Female & 71 & Left & AVN & 47.86 & 0.63 & Caloric test/ vHIT & 33 & 0.79 & 15.2 \\
5 & Female & 51 & Left & AVN & 71.34 & 0.78 & Caloric test/ vHIT & 100 & 1.04 & 10.6 \\
6 & Male & 43 & Right & AVN & 57.88 & 0.71 & Caloric test/ vHIT & 70.14 & 0.88 & 13.0 \\
7 & Male & 37 & Left & AVN & 100 & - & Caloric test & 100 & - & 50.1 \\
8 & Male & 60 & Left & AVN & 67.98 & - & Caloric test & 56.34 & - & 7.1 \\
9 & Female & 57 & Left & AVN & 92.16 & - & Caloric test & 89.21 & - & 6.4 \\
10 & Male & 29 & Right & AVN & 55.69 & 0.77 & vHIT & - & 0.87 & 6.1 \\
11 & Male & 59 & Right & AVN & 100 & 0.65 & vHIT & - & 0.65 & 6.3 \\
12 & Male & 47 & Left & AVN & 69.56 & 0.4 & vHIT & - & 0.59 & 7.0 \\
13 & Female & 56 & Right & AVN & 43.57 & 0.69 & vHIT & - & 0.99 & 9.3 \\
\hline
\end{tabular}

CP: canal paresis, vHIT: video head impulse test, F/U: follow up, AVN: acute vestibular neuritis 
ion. A single right-handed examiner conducted head impulses by rotating the patient's head to the right and left while the patient fixated on a stationary target on the wall at a distance of 1 meter. Head impulses were applied with a peak velocity range of 200 to $250 \%$, rotation amplitude of $15-20^{\circ}$, and duration of 150-200 ms. A minimum of 20 horizontal head impulses were delivered randomly in the right or left direction. The software automatically calculated the gain in VOR. The VHIT was defined as pathological if the mean VOR gain was reduced below a value of 0.8 and overt and/or covert correcting saccades were recorded. In accordance with previous studies, the frequency of re-fixation saccades above $-110 \%$ in at least $80 \%$ of impulses was considered pathological. $^{13,14)}$

To compare the evolution of the caloric test with vHIT, variations of $\mathrm{CP}$ and vHIT gain were calculated for each patient using the following formulas: Variation of $\mathrm{CP}(\triangle \mathrm{CP})=($ followup $\mathrm{CP}$-initial $\mathrm{CP}) /$ initial $\mathrm{CP}$, Variation of gain $(\Delta$ gain $)=($ followup gain-initial gain)/initial gain. ${ }^{15)}$

\section{Statistical analysis}

All statistical analyses were performed using SPSS software for PC, version 21 (IBM Corp., Armonk, NY, USA). Significant differences were determined using Wilcoxon signedrank tests. Additionally, linear regression analysis was performed and correlation coefficients were determined. All tests used a $p$-value $<0.05$ as the cut-off for statistical significance.

\section{Results}

All VN patients in this study were treated with the same conventional vestibular rehabilitation protocol, which included habituation, compensation, and substitution for 1-3 months. Vestibular symptoms recovered during follow-up periods, although there were differences in recovery duration. Results of the caloric tests in the acute and chronic phases were compared in nine patients. The initial mean CP was $75.6 \pm$ $15.5 \%$, and the mean CP in the follow-up test was $76.3 \pm 20.7$ (Fig. 1). The mean follow-up duration was $16.9 \pm 12.4$ months. There were no statistically significant differences in the mean $\mathrm{CP}$ between the initial and the follow-up test $(p=0.889)$. Ten patients underwent vHIT, and their mean gains from each ear were compared. Initially, the mean gain of the affected ear was $0.58 \pm 0.21$ and that of the healthy ear was $0.98 \pm 0.20$. Correcting saccades were present in all patients. Among these, covert saccades were observed in seven of ten patients (70\%), and overt saccades in nine patients (90\%). At the follow-up test, the mean gain of the affected ear had increased significantly, to $0.79 \pm 0.21$, compared to that at the initial test ( $p=$ 0.011). Correcting saccades were found in five of ten patients. Of these, three patients presented covert saccades (30\%) and four patients presented overt saccades (40\%). The mean interval between vHIT tests was $11.7 \pm 12.4$ months. The mean gain of the healthy ear did not differ significantly between the initial and follow-up tests (Fig. 2).

To determine the differences between the two tests, data from the six patients who underwent both tests were sub-an-

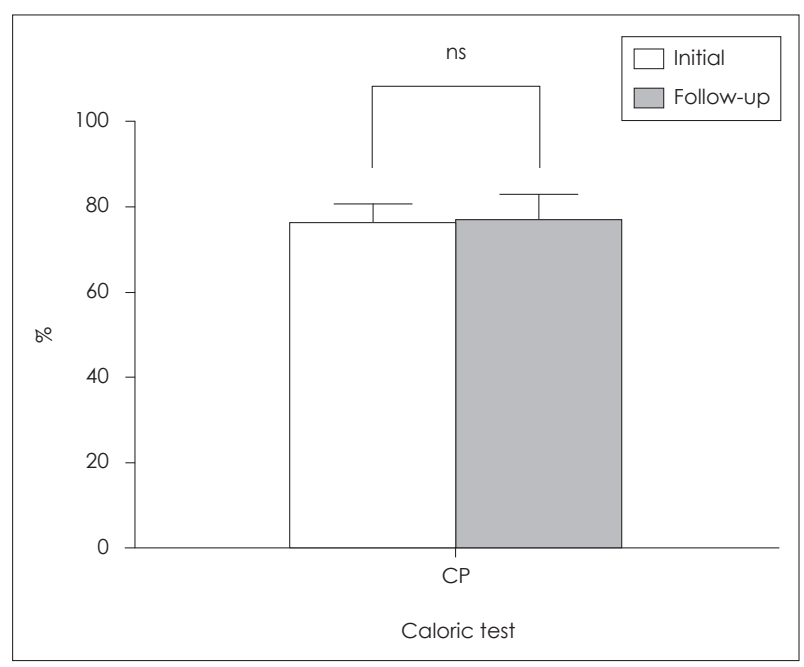

Fig. 1. Comparison of CP from the initial caloric test and at followup. There was no statistically significant change in $\mathrm{CP}$ during the analyzed period $(p=0.889)$. ns: not significant, CP: canal paresis.

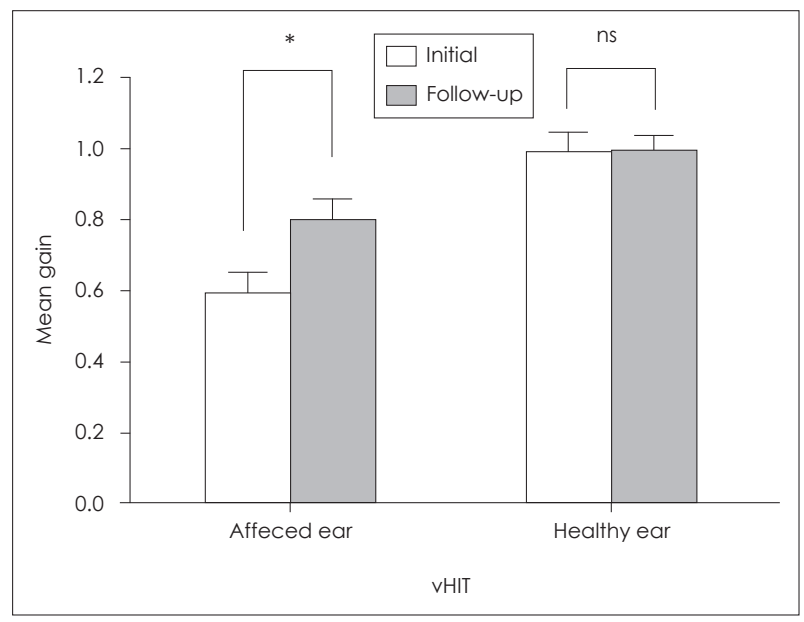

Fig. 2. Comparison of the mean gain of the affected and healthy ear in the initial VHIT and at follow-up. In the affected ear, the gain of the VHIT was increased in most patients, and the mean gain was significantly improved at follow-up. On the other hand, the mean gain of the healthy ear did not differ significantly between the initial and follow-up tests. ${ }^{*} p<0.05$. ns: not significant, vHIT: video head impulse test. 
alyzed. They showed no significant differences in caloric test results between the initial and follow-up tests (CP: 70.0土 $13.3 \%$ and $73.5 \pm 21.1 \%$ at initial and follow-up test, respectively, $p=0.753)$. However, the vHIT showed a statistically significant improvement (mean gain: $0.56 \pm 0.24$ and $0.81 \pm 0.24$ at initial and follow-up test, respectively, $p=0.028$ ). Next, the correlation between variations of $\mathrm{CP}$ in the caloric test and horizontal gain in the vHIT was analyzed, and the improvement of horizontal gain in the vHIT was found to have no linear correlation with variations of $\mathrm{CP}\left(\mathrm{R}^{2}=0.0004, p=0.969\right)$.

\section{Discussion}

This study investigated changes in vestibular function after more than six months in patients with $\mathrm{VN}$ using caloric tests and vHITs. Patients with acute VN showed increased CP in the caloric test and decreased gain in the vHIT results. However, the results of follow-up showed that there were no significant changes in $\mathrm{CP}$ in the chronic phase, whereas the decreased gain of the vHIT showed significant recovery. The results of our study coincided with those of other studies in their results of caloric tests and vHITs. It was previously reported that $50 \%$ of patients with VN had abnormal CP after 5 or 10 years, ${ }^{16)}$ and another study demonstrated that there was no correlation between $\mathrm{CP}$ and chronic symptoms after $\mathrm{VN}{ }^{17)}$ Previous studies investigating head impulses have reported that the horizontal gain increase in head impulses occurred within the first few weeks after onset. ${ }^{18)}$ Using a follow-up period of one year, Magliulo, et al. ${ }^{19)}$ have found that $85.7 \%$ of patients had resumed normal vHIT results. In addition, their multivariate regression analysis revealed that vHIT was significantly associated with clinical symptoms. However, studies assessing both caloric tests and vHIT results, and analyzing the changes between them are limited. Zellhuber, et al. ${ }^{8}$ reported that there was no linear correlation between the gain asymmetry of vHIT and the unilateral weakness of caloric test results in a short-term 3-month analyses of individual and group studies.

In this study, six month or longer follow-up data did not show any linear correlation between changes in $\mathrm{CP}$ of the caloric test and horizontal gain of the vHIT. This suggests that there is no significant relationship between the degree of horizontal gain recovery and CP normalization, implying that vestibular function recovers in a frequency-specific way. Several mechanisms may explain this dissociation. First, vHITs and caloric tests have different temporal frequencies.
The vHIT covers the VOR response with high frequency stimuli $(2-5 \mathrm{~Hz})$, which is more physiologic, while the caloric test covers non-physiological low frequency stimuli (0.002$0.004 \mathrm{~Hz}$ ). The results of animal studies have well-established that the type of nerve fibers activated depends on the frequency of the stimuli. ${ }^{20)}$ Irregular afferents primarily encode high frequency and high acceleration head movements while regular afferents are more likely to encode low frequency and low acceleration movements. ${ }^{21)}$ Therefore, the dissociation between follow-up results of the two tests might reflect that central compensation for VOR impairment differs according to the frequency of the stimulus. Dissociation caused by different stimulus frequencies of these two types of tests has been reported in Ménière's Disease. ${ }^{15)}$

Additionally, these two tests differ not only in their stimulated frequency, but also in their method of stimulation. While the vHIT produces a direct endolymphatic flow through head impulses, the caloric test induces an endolymphatic flow by convection heat transfer. Caloric tests also stimulate the inner ear in a gravity-independent way. Different mechanisms have been proposed such as the pressure change caused by the direct volume displacement with temperature gradient, direct thermal effect on vestibular nerve endings, and modulation of the caloric nystagmus by body position, which is produced by interaction of signals from otolith organs with those of the semicircular canal in the central vestibular nuclei. $^{22)}$ These various mechanisms of stimulation could explain the remaining $\mathrm{CP}$ of the caloric test even after central compensation during follow up periods. Due to these differences between the two tests, the vHIT may be more physiologic than the caloric test. Furthermore, catch-up saccades were found in all patients in the acute phase. However, in the follow-up vHIT, they were observed only in some patients, and their intensity was reduced. Therefore, the vHIT may better reflect vestibular symptoms in daily life during the non-acute phase of VN. Several studies have shown that the vHIT provides information not only about vestibular impairment, but also about the effect of impairment on a patient's quality of life. ${ }^{6,23)}$ Our results also suggest that the vHIT is more likely to be associated with vestibular symptoms than the results of the caloric test in the chronic phase of $\mathrm{VN}$, since the patients' clinical symptoms all improved but only the results of the vHIT showed significant recovery.

The present study had several limitations that prevented us from reaching more definitive conclusions. First, the number of enrolled cases in the present study was small and the 
follow-up period was not controlled. Additionally, there was no quantitative assessment of vestibular symptoms through indices such as the Dizziness Handicap Inventory. Further studies that consider these factors are needed. Obviously, both the vHIT and caloric tests are representative test modalities for dynamic VOR, and can provide complementary information on horizontal canal function because they stimulate different frequencies of head movement.

In conclusion, In the acute phase of $\mathrm{VN}, \mathrm{CP}$ of the caloric test was increased, and the gain of the vHIT in the affected ear was decreased. Long-term follow-up showed relatively fast recovery of vHIT gain, whereas the results of the caloric test did not significantly improve. Our results suggest that the vHIT could better reflect vestibular symptoms in the nonacute phase of VN than the caloric test. However, since these two tests use different stimulus frequencies and show different recovery rates, the caloric test and the vHIT should be combined to cover a broader spectrum of frequencies and test vestibular function more precisely.

\section{Acknowledgments}

The authors declare no competing interests. This work was supported by by Yonsei University College of Medicine grant funded by the Dongwha industry (6-2016-0128).

\section{REFERENCES}

1) Dix MR, Hallpike CS. The pathology, symptomatology and diagnosis of certain common disorders of the vestibular system. Ann Otol Rhinol Laryngol 1952;61(4):987-1016.

2) Strupp M, Magnusson M. Acute unilateral vestibulopathy. Neurol Clin 2015;33(3):669-85.

3) Adamec I, Krbot Skorić M, Handžić J, Habek M. Incidence, seasonality and comorbidity in vestibular neuritis. Neurol Sci 2015;36(1):91-5.

4) Strupp M, Zingler VC, Arbusow V, Niklas D, Maag KP, Dieterich $\mathrm{M}$, et al. Methylprednisolone, valacyclovir, or the combination for vestibular neuritis. N Engl J Med 2004;351(4):354-61.

5) Weber KP, MacDougall HG, Halmagyi GM, Curthoys IS. Impulsive testing of semicircular-canal function using video-oculography. Ann N Y Acad Sci 2009;1164:486-91.

6) Jorns-Häderli M, Straumann D, Palla A. Accuracy of the bedside head impulse test in detecting vestibular hypofunction. J Neurol Neurosurg Psychiatry 2007;78(10):1113-8.

7) Bartolomeo M, Biboulet R, Pierre G, Mondain M, Uziel A, Venail F. Value of the video head impulse test in assessing vestibular deficits following vestibular neuritis. Eur Arch Otorhinolaryngol 2014;271 (4):681-8.

8) Zellhuber S, Mahringer A, Rambold HA. Relation of video-headimpulse test and caloric irrigation: a study on the recovery in unilateral vestibular neuritis. Eur Arch Otorhinolaryngol 2014;271(9):237583.

9) Mahringer A, Rambold HA. Caloric test and video-head-impulse: a study of vertigo/dizziness patients in a community hospital. Eur Arch Otorhinolaryngol 2014;271(3):463-72.

10) Choi KD, Oh SY, Kim HJ, Koo JW, Cho BM, Kim JS. Recovery of vestibular imbalances after vestibular neuritis. Laryngoscope 2007; 117(7):1307-12.

11) Jung J, Suh MJ, Kim SH. Discrepancies between video head impulse and caloric tests in patients with enlarged vestibular aqueduct. Laryngoscope 2017;127(4):921-6.

12) Jongkees LB, Maas JP, Philipszoon AJ. Clinical nystagmography. a detailed study of electro-nystagmography in 341 patients with vertigo. Pract Otorhinolaryngol (Basel) 1962;24:65-93.

13) Matiño-Soler E, Esteller-More E, Martin-Sanchez JC, MartinezSanchez JM, Perez-Fernandez N. Normative data on angular vestibuloocular responses in the yaw axis measured using the video head impulse test. Otol Neurotol 2015;36(3):466-71.

14) Rambold HA. Age-related refixating saccades in the three-dimensional video-head-impulse test: source and dissociation from unilateral vestibular failure. Otol Neurotol 2016;37(2):171-8.

15) Redondo-Martínez J, Bécares-Martínez C, Orts-Alborch M, GarcíaCallejo FJ, Pérez-Carbonell T, Marco-Algarra J. Relationship between video head impulse test (vHIT) and caloric test in patients with vestibular neuritis. Acta Otorrinolaringol Esp 2016;67(3):156-61.

16) Okinaka Y, Sekitani T, Okazaki H, Miura M, Tahara T. Progress of caloric response of vestibular neuronitis. Acta Otolaryngol Suppl 1993;503:18-22.

17) Bergenius J, Perols O. Vestibular neuritis: a follow-up study. Acta Otolaryngol 1999;119(8):895-9.

18) Palla A, Straumann D. Recovery of the high-acceleration vestibuloocular reflex after vestibular neuritis. J Assoc Res Otolaryngol 2004; 5(4):427-35.

19) Magliulo G, Iannella G, Gagliardi S, Re M. A 1-year follow-up study with C-VEMPs, O-VEMPs and video head impulse testing in vestibular neuritis. Eur Arch Otorhinolaryngol 2015;272(11):3277-81.

20) Haque A, Angelaki DE, Dickman JD. Spatial tuning and dynamics of vestibular semicircular canal afferents in rhesus monkeys. Exp Brain Res 2004;155(1):81-90.

21) Hullar TE, Della Santina CC, Hirvonen T, Lasker DM, Carey JP, Minor LB. Responses of irregularly discharging chinchilla semicircular canal vestibular-nerve afferents during high-frequency head rotations. J Neurophysiol 2005;93(5):2777-86.

22) Scherer H, Clarke AH. The caloric vestibular reaction in space. physiological considerations. Acta Otolaryngol 1985;100(5-6):328-36.

23) Batuecas-Caletrio A, Santacruz-Ruiz S, Muñoz-Herrera A, PerezFernandez N. The vestibulo-ocular reflex and subjective balance after vestibular schwannoma surgery. Laryngoscope 2014;124(6):1431-5. 